\title{
Alan Solem's work on the diversity of Australasian land snails: an unfinished project of global significance
}

\author{
R.A.D. Cameron ${ }^{1}$, B.M. Pokryszko ${ }^{2}$ and F.E. Wells ${ }^{3}$ \\ ${ }^{1}$ Department of Animal and Plant Sciences, University of Sheffield, Sheffield S10 2TN, UK, \\ and Department of Zoology, The Natural History Museum, London SW7 5BD, UK \\ (address for correspondence) Email: r.cameron@sheffield.ac.uk \\ ${ }^{2}$ Museum of Natural History, Wroclaw University, Sienkiewicza 21, 50-335 Wroclaw, Poland \\ ${ }^{3}$ Western Australian Museum, 1 Francis Street, Perth 6000, Western Australia
}

\begin{abstract}
Alan Solem's systematic work focused on Pacific island Endodontoidea and on Australian Camaenidae. His many papers on these taxa deal with 647 species (329 new) and 136 genera. His descriptions and identification criteria are detailed and clear. Though not a formal cladist, his interpretation of characters shows that his approach was intuitively cladistic, and his phylogenies are likely to survive formal analysis. His comprehensive revisions, and his cataloguing of whole faunas enabled him to analyse patterns of distribution, and to relate them to evolutionary, biogeographic and ecological theory. For the Pacific Islands, he exposed the limitations of the equilibrium theory of MacArthur and Wilson, drawing attention to its neglect of in situ speciation. In Australia, he identified many cases of remarkable allopatric distributions amongst camaenid genera and species, many of which have minute geographical ranges. Because he studied the whole fauna, and achieved remarkable geographical coverage, he could contrast these patterns with those seen in other families, and in the much richer faunas he studied in New Zealand, where many congeners coexist. He used his experience as a basis for a global review of land snail diversity. Some of the questions and ideas he raised are discussed here and elsewhere in the symposium. At the time of his death, Solem was working on the description of more material (8-10 genera and c. 100 species), and had started to explore the evolutionary events underlying these contrasts. Both his described and undescribed materials are available in WAM and FMNH, and offer the opportunity for cladistic and molecular analysis, answering questions of theoretical and conservation concern. His work has already informed conservation planning in Western Australia. Snail faunas are good general indicators of conservation value, and the completion of his work will further aid conservation planning.
\end{abstract}

Key words: Alan Solem, Australasian land snails, diversity.

\section{INTRODUCTION}

Land snails constitute a significant and characteristic element of the world's terrestrial fauna, and may be the most diverse group after arthropods and nematodes. They feature rather seldom, however, in general accounts of biodiversity and its causes, despite the fact that they appear to be amongst the most vulnerable to human-induced extinction (Groombridge, 1992). Amongst other reasons, this results from our very incomplete, and often confused, knowledge of snail systematics and from the great variety of patterns of distribution and diversity found between regions, and amongst different groups of snails.

Alan Solem was the first person to attempt a global synthesis (Solem, 1984a). While it is certainly incomplete, and in particular instances has proved to be wrong, it has set an agenda, raising questions of global significance, and providing much of the material on which answers can be based. The stimulus for his synthesis came from his intensive studies in Australasia, where his excellent systematic and ecological work prompted questions about the patterns revealed. Both his basic systematic work, and his exploration of causes for patterns were incomplete at the time of his death in 1990. In this paper, we outline his achievements in the systematics and in the biogeography of Australasian land snails; we examine his contribution to the understanding of global patterns, and we draw attention to his undescribed material and unfinished business which offer excellent prospects for further studies. 


\section{SYSTEMATICS}

Alan Solem dealt with a variety of taxa from many different areas, but he spent most of his systematic life studying Endodontidae and Charopidae (mostly from Pacific Islands) and Australian Camaenidae (as well as some other taxa, mostly Pupilloidea). His interest in these taxa and areas started more or less at the same time. The opening paper of the endodontoid series (Endodontidae of the Philippines) was published in 1957. The series culminated in publication of his monumental work on the Pacific endodontoids in two parts: I. - Endodontidae published in 1976, II Punctidae and Charopidae - in 1983. The total number of papers on Endodontidae produced in that period was 18. The first paper of the Australian series (1958) is a description of a new land snail from Queensland. Nearly half of the 28 papers on Australian snails (13) deal exclusively with camaenids. Apart from smaller contributions, they include a series of eight mongraphs of Camaenidae from various parts of Australia, seven of them bearing consecutive numbers (I - 1979, Camaenidae of trans-Australian distribution, II - 1981, Kimberley, III - 1981, Ningbing Ranges and nearby areas, IV - 1984, Kimberley Westraltrachia, V - 1985, remaining Kimberley genera, VI - 1993, Red Centre, VII - 1997, Dampierland through to Nullarbor), all published as supplements to the Records of the Western Australian Museum, and an odd volume (1992, south and eastern South Australia, excluding Kangaroo Island), published in the monograph series of the Records of the South Australian Museum. The later volumes were published posthumously. Ten of the 46 publications dealing with either Australia or Pacific endodontoids are book-sized monographs, of a few hundred pages each.

His work on Pacific endodontoids was based on materials from a variety of collections, but mostly from the Bishop Museum. In contrast, most of his taxonomic research in Australia was based on material he collected during his own fieldwork. He worked in Australia from 1974 till his death on February $26^{\text {th }} 1990$, on an almost annual basis, and collected in the western two-thirds of the continent. In addition, he stayed in Kimberley over a full year during 1976-77. The stay included a full monsoonal wet season and resulted in a study on camaenid
Table 1 Number of species described by Alan Solem and his predecessors in selected families.

\begin{tabular}{lcc}
\hline Taxon & $\begin{array}{c}\text { Number of } \\
\text { species known } \\
\text { before Solem }\end{array}$ & $\begin{array}{c}\text { Number of } \\
\text { species described } \\
\text { by Solem }\end{array}$ \\
\hline Australian Camaenidae & 124 & 187 \\
Pacific Endodontidae & 71 & 89 \\
Pacific Charopidae & 44 & 43 \\
\hline
\end{tabular}

reproductive cycles and growth patterns (Solem and Christensen, 1984). The resulting collections, which have been split between the Western Australian Museum, the Field Museum of Natural History, Chicago and other appropriate museums, contain the taxa on which Solem focused (all his voucher specimens, including types) but also many taxa yet to be examined; $8-10$ genera and around 100 species of Kimberley camaenids await formal description.

The extent of his achievement for these groups is massive (Table 1). He described a total of 329 species and 63 genera, and revised 318 species and 73 generic taxa from Australia and Pacific Islands (Tables 2,3). The total number of new species and genera described testifies to the amount of work, but again shows how little these families had been studied previously.

Solem's first and greatest merit was the quality of description. His descriptions are detailed, exact and unequivocal. In most cases they consider both shell and genitalia and - whenever possible - include a detailed analysis of variation. They are accompanied by notes on ecology, distribution and all sorts of taxonomic remarks on identity of types, nomenclature problems etc. One of us (RADC) can testify that, faced with a totally unfamiliar fauna for the first time, the use of Solem's monographs made identification more straightforward than, on occasions, it proved to be in more familiar territory (Cameron, 1992). An average description in Solem's camaenid monographs is about four hundred pages (figures included), an average description of a species for which variation is discussed - seven or eight pages. Analysing variation implies studying extensive material of each species (Table 4) - an attitude not very popular among systematists. In his endodontoid monograph, Solem provides

Table 2 Australian taxa revised and described by Solem.

\begin{tabular}{|c|c|c|c|c|c|c|}
\hline \multirow[t]{2}{*}{ Taxa } & \multicolumn{2}{|l|}{ Camaenids } & \multicolumn{2}{|c|}{ Non camaenids } & \multicolumn{2}{|l|}{ Total } \\
\hline & New & Total & New & Total & New & Total \\
\hline Families & $\begin{array}{l}1 \\
\text { (subfamily) }\end{array}$ & 1 & - & 17 & $\begin{array}{l}1 \\
\text { (subfamily) }\end{array}$ & 18 \\
\hline Genera & 22 & 57 & 3 & 35 & 25 & 92 \\
\hline Species & 187 & 321 & 11 & 70 & 198 & 391 \\
\hline
\end{tabular}


Table 3 Pacific Islands taxa revised and described by Solem.

\begin{tabular}{lllllll}
\hline Taxa & \multicolumn{2}{c}{ Endodontidae } & \multicolumn{2}{c}{ Charopidae } & \multicolumn{2}{c}{ Total } \\
& New & Total & New & Total & New & Total \\
\hline $\begin{array}{l}\text { Families/ } \\
\text { subfamilies }\end{array}$ & 0 & 1 & 2 & 1 & 2 & 2 \\
$\begin{array}{l}\text { Genera } \\
\text { Species }\end{array}$ & 19 & 24 & 19 & 20 & 38 & 44 \\
& 88 & 169 & 43 & 87 & 131 & 256 \\
\hline
\end{tabular}

Table 4 Mean number of examined specimens of species whose variation was discussed in Solem's papers (species selected at random).

\begin{tabular}{lllc} 
Taxon & $\begin{array}{l}\text { Number } \\
\text { of } \\
\text { species }\end{array}$ & $\begin{array}{l}\text { Total number } \\
\text { of specimens } \\
\text { examined }\end{array}$ & $\begin{array}{l}\text { Mean number } \\
\text { of specimens } \\
\text { examined per } \\
\text { species }\end{array}$ \\
\hline Pupilloidea & 10 & 1,242 & 124.2 \\
Camaenidae & 20 & 4,532 & 226.6 \\
Endodontidae & 20 & 2,936 & 146.8 \\
\hline
\end{tabular}

geographical variation data for over $90 \%$ of species discussed.

Solem's papers on Australian and Pacific Island snails contain a total of 647 species descriptions/ redescriptions and 136 generic accounts. Even a very efficient and experienced scientist, with considerable help from technicians, would need at least a week to examine a few dozen (sometimes a few hundred) shells, and do dissections, statistics and drawings for a single species. And this is apart from visiting museums, literature research and correspondence about loans. Multiply this by 647 (= 4529 days!) and divide by 365 , and you will end up over 12 years of purely descriptive work.

Solem clearly enjoyed this part of his work. $\mathrm{He}$ also had a knack for seeing new characters (characters nobody had looked for, not to mention made use of) and knew where to look for them. Micro-denticulations on apertural barriers and micro-components of shell sculpture (Endodontidae, Camaenidae, Pupilloidea), ovotestis structure, course and degree of coiling of hermaphroditic duct, terminal female genitalia (Camaenidae, Endodontidae) provide good examples. Systematists started using electron microscopes in the 1960s. Solem's systematic publications of 1970-1973 (the first one on malacological applications of scanning electron microscopy, another three on apertural barriers and radulae) are among pioneer works dealing with SEM application in systematics. He also looked critically at the use of standard characters, especially in the genitalia, demonstrating seasonal variation in morphometric variables (Solem and Christensen, 1984).

Reading descriptions of new taxa per se is often boring, unless it is the reader's favourite taxon that is concerned. Not so with Solem's descriptions. He liked to give his new taxa fancy names. Two endodontid genera were christened Zyzzyxdonta and Aaadonta, with the following justification: "Species of the genus Aaadonta represent the extreme development of fine sculpture and have the westernmost range of existing Endodontidae. The single known species of $Z y z z y x d o n t a$ represents the extreme gross sculptural development within the family and is at the southwestern fringe of distribution. It was thought appropriate that their names should be as widely separated as their sculpture". Another example is Ba humbugi from Fiji. "Because it occupies a portion of Viti Levu that includes the Mba District, I have chosen the European spelling of the district for a generic name. This was followed by an irresistible impulse to use the specific name humbugi".

Being author of over 300 species names, Solem was by no means a species-monger. It is enough to look at references and the number of examined types for species he revised. Among a hundred randomly selected species revised by him (Endodontidae, Camaenidae, Pupilloidea), the mean number of references (synonyms, or mentions in literature) per species is 4.05 . In 79 cases out of 100 , type series were examined (for species with many synonyms types of at least one synonymous name) and lectotypes designated.

Revision of species already known was as important as describing new ones, if not more. Most of the total of 318 species Solem revised were described in the $19^{\text {th }}$ and the first half of $20^{\text {th }}$ century, very often inadequately, needing a re-description, and in most cases type series were difficult to locate. He provided synonymies, good descriptions, figures, and - for many of them - comments on variation; in most cases he managed to locate the types. The revisionary work must have been especially difficult in Australia where Solem had to deal with Iredale's notorious descriptions and generic classification.

Methodological chapters of Solem's monographs show his great concern for criteria for recognising species and higher taxa. The chapter "Criteria for species recognition" in his endodontoid monograph contains not formal and/or philosophical general criteria (which is often the case with systematists), but practical anatomical and morphological justification for recognising more than one species in the case of congeneric sympatric species and several sympatric species of different genera; even instances when he recognises subspecies are explained and justified. The generic criteria, apart from an obvious concern for monophyly, show some influence of the classical evolutionary way of thinking: "A major concern has been to try and establish comparability of generic units, to make 
'generic level differentiation' represent a roughly equivalent degree of change throughout a family." Although terms like "phylogeny", "phylogenetic analysis" or "computer-generated phylogeny" figure in his papers, he never declared himself as a cladist. He did not use formalised cladistic analysis, nor did he produce character matrices and then cladograms with consistency index or retention index indicated. In 1976 he wrote "Perhaps the key problem in phylogenetic analysis today is the question of how to weight characters in determining phylogeny. Opinions vary from the classical pheneticists who stated that every character is of equal weight, to the classical typologists who picked out single characters on which to base decisions. In between are the vast majority of systematists. The present study is more pragmatic than philosophical ...".

His ideas about reconstructing phylogeny had been already developed at that time, but were published slightly later (Solem, 1978). He calls his approach a "tiered" one, with major changes involved in progressive evolution (adaptive shifts) requiring changes in ecological roles accompanied by morphological alterations, adaptive radiations constituting the intermediate level, and interactions between sympatric species producing yet a third level of evolutionary change. Polarity of characters is never mentioned, and the exact way Solem generated his phylogenies (and some of the diagrams in his monographs are captioned "computer-generated phylogeny, 'combinatorial' method") is not discussed. It can be only conjectured, based on his phylogenetic discussions and conclusions, that his approach was intuitively cladistic. The chapter title like "Portrait of a generalized endodontoid" followed by "Identifiable major trends" is the best proof. The character analysis in all his papers concerned with phylogeny is very detailed; each character is considered in the context of an ancestral character state (the "generalized endodontid") and subsequent evolution. Solem interpreted the direction of evolution of many characters by ontogeny (wherever he had various growth stages at his disposal), for example endodontoid apertural barriers and shell sculpture. Thus the characters are polarised, though not explicitly so, and homology versus non-homology as well as instances of convergent evolution are recognised. Solem's monograph of Endodontidae was published in 1976, only ten years after Hennig's "Phylogenetic systematics" and ten years before the first cladistic programme, (Hennig,86) became available.

Most of Solem's phylogenetic work focused on endodontoids. He proposed phylogenies for several species groups within Endodontidae. His phylogenetic approach to camaenids and charopids was limited to defining family- and genus-level taxa, and ensuring their monophyly. By proposing phylogenies, defining families and genera, he provided hypotheses that can now be tested with different methods and with new characters. Because his character analysis is always so detailed, it is perfectly possible to construct a matrix and reconstruct the phylogenies in a strictly cladistic manner. It is very likely that most of his phylogenetic interpretations would prove sound and suffer only minor alterations.

The way Solem interpreted characters of his snails related not only to his phylogenetic interpretations. Another quite natural outcome was evolutionary (and sometimes also functional) interpretation of the observed character distribution patterns and very good reconstructions of growth patterns. Examples are: evolution of apertural barriers, evolution, growth and variation patterns of endodontoid shell sculpture, shell shape evolution and brood chamber formation, hypotheses on possible role of apertural barriers and their microsculpture, or correlating growth patterns with activity periods.

\section{BIOGEOGRAPHY AND THE MECHANICS OF DIVERSITY}

Both in the field, and when reviewing literature, Solem was concerned not only with the description or revision of the taxa on which he was working, but also on gaining an accurate view of their geographical distribution. He also collected the whole molluscan fauna in the sites he visited, and inspired those who worked with him to do likewise. Coupled with the systematic geographical coverage of his fieldwork, this enabled him to expose patterns of distribution as a first step in understanding the processes involved in generating diversity. The extent of this coverage is shown in the pioneering sets of computer-generated distribution maps he prodiced for the fauna of the western two-thirds of Australia (Solem, 1991a and b, 1992).

He naturally started to analyse the patterns revealed, and to relate them to evolutionary, biogeographic and ecological theory. This in turn led him to design programmes of study that would expose particular ideas to testing. Such analyses were clearly under way by the early 1980s; they show in his contribution to the debates over vicariance biogeography (Solem, 1981c), in the biogeographic analyses at the end of his monograph on Pacific Island endodontoids (Solem, 1983), and most evidently in his review in World-wide Snails (Solem, 1984a). By then, he had at his disposal the results of most of his work in Western Australia, and of his study of the phenomenally rich faunas of the Manukau peninsula on North Island, New Zealand (Solem, Climo and Roscoe, 1981; Solem and Climo, 1985). 
Table 5 Total recorded snail fauna (N), and the mean number of species per site, split between Camaenidae and others, for two parts of the Kimberley. Data for the Napiers and Oscars from Cameron (1992); for rainforest from Solem (1991a and b). The data for pupilloids are included in the "non-camaenid" figures; they are separated to show that the most numerous higher taxon is typical.

\begin{tabular}{lccccccc} 
& & \multicolumn{2}{c}{ Camaenids } & \multicolumn{2}{c}{ Pupilloids } & \multicolumn{2}{c}{$\begin{array}{c}\text { All non-camaenid } \\
\text { mean }\end{array}$} \\
\hline Region & sites & N & mean & N & mean & N & meancy \\
Napiers/Oscars & 54 & 22 & 2.24 & 6 & 2.64 & 11 & 5.31 \\
Rainforests & 95 & 97 & 3.40 & 8 & 3.10 & 22 & 8.30 \\
\hline
\end{tabular}

Solem was first and foremost a malacologist, not a theoretician. As such, he adopted what could be described as the "nitpicker naturalist" approach to general theories, valuing them to the extent that they explained his facts to his satisfaction. Naturally, they often failed to do so. The classic example in this respect was his dissatisfaction with the MacArthur and Wilson theory of island biogeography. Despite the fact that the data he presented for Pacific islands (Solem, 1983) do show a species/area relationship (Cowie, 1996), albeit with a very large variance, he argued strongly that such a relationship was at best trivial. He then explored other determinants of diversity such as altitude, age and isolation (Solem, 1983, 1984a, 1990a). While, as Cowie $(1995,1996)$ has demonstrated, he carried scepticism too far, he had recognised a major limitation in the original formulation of the theory, which neglected in situ speciation. He was also aware, from his own studies, of the very small areas sufficient to maintain minimum viable populations of land snails: a small but topographically varied island is the equivalent of a continent. Others would later follow his lead (Cameron, Cook and Hallows, 1996).

This awareness of the small areas in which snail species could survive was reinforced by his studies of Australian snails. It is here that his recording of all the fauna in any locality, coupled with the intensity of his geographical coverage paid dividends. His detailed studies of Camaenidae revealed patterns of distribution that contrasted strongly with those seen in all other taxa (Table 5). Amongst camaenids in the Kimberley there were patterns of microallopatric replacement that generated very high levels of regional diversity, while site diversities remained low (Solem, 1985, 1988, 1991a). By contrast, regional diversity in other families was modest, but site diversities were significantly higher. His naturalist's knowledge of the habits of particular species enabled him to correlate the distributions of different camaenid species with their way of life, contrasting the very restricted ranges of species feeding on algal blooms on rock faces (Westraltrachia and the genera of the Ningbing Ranges) with the broader ranges of species in genera capable of survival in the flood and fire-prone plains (Solem, 1985, 1988).
Table 6 Numbers of cases in which camaenid genera are represented by given numbers of species at a site in Kimberley rainforests. Data from Solem and McKenzie (1991).

\begin{tabular}{lllll}
\hline Species/genus & 1 & 2 & 3 & $4+$ \\
No. of cases & 224 & 22 & 5 & 0 \\
\hline
\end{tabular}

In the Napier and Oscar Ranges, SW Kimberley, he was able to demonstrate character displacement in diet and anatomy in areas of overlap between genera with different evolutionary histories and points of origin (Solem, 1985). In his later studies in the Kimberley rainforest patches (Solem, 1991; Solem and McKenzie, 1991), he could demonstrate that local camaenid faunas usually contained only one species in each genus represented (Table 6). This astonishing radiation is still incompletely studied: not only are many taxa partly described, but not yet named, but only about $10 \%$ of the available rainforest patches have been surveyed. This pattern could in turn be contrasted with that seen in the Ningbing Ranges (Solem, 1988), where each site typically contained only a single camaenid species; three allopatric genera split the Ranges between them, and within each generic range there were a set of allopatrically replacing species, some with minute geographical ranges (Table 7). As he makes clear, what we see here is a dynamic evolutionary radiation in progress, not tiny relict populations on the way to extinction.

These various patterns call for explanations, both in terms of the nature and timing of the evolutionary events involved, and of the underlying pattern of environmental conditions that produced them. While we know something about

Table 7 Geographical ranges of species in the three camaenid genera in the Ningbing Ranges. Figures given are linear distances of habitable terrain in kilometres. Data from Solem (1988), which also gives estimates of areal ranges.

\begin{tabular}{lcccc}
\hline Genus & $\begin{array}{l}\text { Median } \\
\text { Range }\end{array}$ & Minimum & Maximum & $\begin{array}{l}\text { No. of } \\
\text { Species }\end{array}$ \\
\hline Ningbingia & 1.7 & 0.1 & 5.0 & 6 \\
Turgenitubulus & 1.9 & 0.2 & 6.1 & 8 \\
Cristilabrum & 1.4 & 0.5 & 5.0 & 12 \\
\hline
\end{tabular}


environmental changes in the region (Cameron, 1992), the sequence of evolutionary events is still in the realm of speculation. Solem had started to address this with allozyme studies on Ningbing camaenids (Woodruff and Solem, 1990). Had he lived, he would surely have harnessed the energies of a molecular lab to his project, which remains open. The problems are not parochial; microallopatric radiations of closely-related species are known from several parts of the world: Albinaria and Mastus, some Helicoidea in the Aegean (Mylonas et al., 2004), various families in East Africa (Seddon et al. this volume), chondrinids in the Pyrenees (Gittenberger, 1973), and others on (and within) many oceanic islands. It seems likely that analysis will reveal cases of explosive radiation where a range is fragmented, a procedural and analytical challenge to conventional cladistic analysis (Parmakelis and Pfenninger, in prep.).

Where allopatry alone is involved, we have what Gittenberger (1991) has aptly called non-adaptive radiation. In the Kimberley, however, perhaps more than anywhere else so far known, we have, within a single family, a variety of patterns associated with varying environments and taxa. Many fundamental questions relating to the evolution of diversity can be addressed using this fauna. Apart from the patterns mentioned above, the rainforest studies in the Kimberley included some island faunas. Many islands remain to be explored, and the material from others is still undescribed.

It is clear that the visit to the Manukau peninsula, North Island, New Zealand, had a profound effect on Solem's thinking on diversity, emphasising the contrast between the patterns seen in Australian camaenids and the small, mostly litter-dwelling groups he had studied on Pacific islands, which were also represented in the New Zealand faunas (Solem, Climo and Roscoe, 1991; Solem and Climo, 1985). Here, exceptionally rich local faunas contained many small and similar species, often members of the same genus. Local diversity was around 5-10 times as great as he had recorded in Australia. This contrast provoked a global review of local diversity levels, and an attempt to provide an overall synthesis (Solem, 1984a). For this, he corresponded with colleagues all over the world to gather data.

In retrospect, this review can seem theoretically naïve. Certainly, he and his correspondents proved wrong on one count: we now know that tropical rainforest, even with very oligotrophic soils, can support very rich local faunas, indeed the richest so far known (Emberton, 1995; de Winter and Gittenberger, 1999; Schilthuizen and Rutjes, 2001). He created the rather shaky concept of "mosaic" diversity, as distinct from true microsympatry, to explain the relatively high levels of site diversity recorded in temperate zone forests from Europe and N. America, yet work already published (Schmid, 1966) had revealed up to 35 species coexisting in a single square metre of temperate forest. Later work (Nekola and Smith, 1999; Nekola, this volume; Pokryszko and Cameron, this volume) confirms those early findings.

Nevertheless, the New Zealand faunas remain amongst the richest known, and are set in an outstandingly rich regional fauna (Barker and Mayhill, 1999; Barker, this volume). Allowing for possible major taxonomic revisions, these faunas, and others in subtropical eastern Australia (Stanisic, 1994, 1997; Stanisic and Ponder, 2004), or in parts of tropical Africa (Tattersfield, 1998; Seddon et al., this volume), often show many closely-related and morphologically similar species coexisting. Solem attributed this build-up of sympatric diversity to the stability and suitability of environmental conditions. By implication, it involved repeated cycles of isolation by distance, differentiation and back-migration over periods longer than the Pliocene/Pleistocene climatic oscillations that seem to affect faunas in more marginal environments.

This work highlights some fundamental theoretical concerns. When we consider the species richness of any major taxon at site level, $\alpha$ diversity, how do we interpret it? Is it determined by competitive interactions? Or by accumulation of largely non-interactive entities, dependent on history and biogeographical possibility? One of the central messages that Solem leaves us is that both may be true within the same fauna; all snails are not alike, nor are all contexts. In Australia, camaenids do one thing, other taxa something else. An aggregation of taxa in the category "snails" may obscure radical differences within the chosen group. Later work shows that even within a family, patterns of diversity differ with context. In Mediterranean Crete, where aridity is a significant factor, rock-dwelling Clausiliidae show a pattern of allopatric replacement within the only available genus (Albinaria) (Mylonas et al., 2004). In Carpathian forests (Pokryszko and Cameron, this volume), by contrast, single plots may contain up to 10 of the 20 clausiliid species regionally available, distributed amongst several genera.

As such patterns emerge from studies across the world, we can start to make suggestions. For example, Cameron and Cook (2001) suggested that the radiation in Madeiran forests, where many congeners coexist, is older than that in dry coastal regions where allopatric replacement is more frequent. Tattersfield (1998) shows an intriguing mixture of patterns in Tanzanian coast forest Gulella: both restriction of species to particular forests, and many sympatric species in each. Patterns are different again in tropical forests where there are radiations in large and conspicuous species, as in Sri Lanka (Naggs and Raheem, this 
volume). All the contributions to this volume bear on these fundamental questions. Increasingly, it seems likely that some differences between faunas are a product of phylogenetic constraint rather than perfect local adaptation (Emberton, 1995).

Solem's naturalist's approach can be contrasted with more abstract, conceptual approaches. One such development of biogeography is the field of Macroecology. Blackburn and Gaston (2003) introduce their edited volume thus:

"The past decade has seen the flowering of a bold and distinctive research programme in ecology that is concerned with thinking big. It is the ecology of wide expanses of space, long periods of time and large numbers of taxa. In a word, coined by Jim Brown and Brian Maurer, it is the discipline of macroecology".

As with the theoretical biogeography of MacArthur and Wilson that preceded it, the search for general, high-order rules relating to the creation and maintenance of diversity is surely worthwhile. Its approach, however, necessitates reducing species in all their diversity of habits and history into equivalent digits of statistically treatable data; numbers are all. Of course, notice is taken of the manifest differences between major taxa: no one conflates snails and birds. Solem's contribution is to remind us that species and situations differ, between families or even between genera. His approach is basically "bottom up", delighting in the singularities and peculiarities of snails. Martins (this volume) explores the way in which we can use detailed examples to understand broader patterns. It is interesting to note that at least one significant contributor to recent theoretical debates calls for a similar approach in the field of island biogeography (Lomolino, 2000), a call followed up by contributors to this volume (Triantis et al. 2003; and this volume). Solem's legacy in diversity studies is a set of pertinent, but as yet unanswered questions about the patterns of diversity we see in land mollusc faunas.

\section{CONSERVATION}

Good systematics is a prerequisite to good conservation policy, especially in poorly studied areas where we exterminate living creatures before we manage to study and describe them. Solem himself was very aware of this; much of his work on Pacific Island snails was based on earlier collections of species extinct by the time he came to study them. Included in his publications is a heartfelt plea for the fauna of Hawaii (Solem, 1990b).

Oceanic island endemics, of any taxon, have restricted ranges. On continental landmasses, national parks and nature reserves worldwide are based largely on vertebrates, or on plants, partly because the knowledge of invertebrate requirements and distribution ranges is still too scanty. Concern to create large enough reserves to support minimum viable populations of large, mobile animals, and to avoid a high proportion of edges or transitions has favoured the "few, but large" reserve policy over "many, but small".

As a result of Alan Solem's land snail work in Australia, substantial conservation issues were raised. Until his time, Western Australian terrestrial parks and reserves were based largely on vertebrates, which are typically large and wideranging. Simply knowing what is there has an impact: the Western Australian list of Fauna that is rare or is likely to become extinct includes 34 snail species (some from the Ningbings, see below); 30 of these were described by Solem. His systematic and biogeographic research (see above) showed that while some snail species are widely distributed, many have very restricted ranges. The most extreme example is the Ningbing Ranges and Jeremiah hills in the Kimberley (Solem, 1988). In this area, with its series of low rock outcrops in otherwise flat, open country that is difficult for land snails to traverse, Solem found 28 mainly allopatric species over the $52 \mathrm{~km}$ extent of the ranges. He gave some talks where he showed a baobab tree with one species on the left of the tree, one on the right; the smallest-ranged subspecies had a total range in the world of $0.01 \mathrm{~km}^{2}$ !

More recent work on other invertebrate groups indicates that the pattern of small-scale distribution that Solem found in land snails applies to other groups. For example, Dr Mark Harvey of the Western Australian Museum found 500 species of spiders, almost all with small ranges and undescribed. This kind of information changed the Western Australian thinking about management of protected areas. CALM has subsequently monitored the Kimberley area and other areas where Solem worked, and found human activities (fires, grazing) are affecting the habitats. Solem himself complained about the activities of "pyromaniac pastoralists" (Solem, in litt. to RADC).

Following Solem, similar concerns have been raised for other continental faunas (Tattersfield, 1998). His data raise crucial questions about conservation choices (Cameron, 1998). The search for surrogates or indicators of conservation value when complete surveys are impracticable has revealed that, in an Australian context, endemic snail faunas are a good predictor of value for other groups (Moritz et al., 2001).

\section{CODA}

Alan Solem died suddenly. He was not old and, unlike many people, had no time to finish, publish, tidy up, proofread, label, distribute and arrange. At 
the time of his death, he was working on describing 8-10 new genera and about 100 new species of camaenids. The material came from two sources: the 1988 WAM-FMNH trip to the Kimberley islands, and the survey of rainforest patches in the Kimberley conducted by the WA Department of Conservation and Land Management (CALM) (Solem, 1991a). Despite efforts to attract a systematist to work on these, they remain undescribed, and are still available for description in WAM and FMNH. Much of the material is suitable for molecular analysis, and the geographical patterns already described provide a basis for studying the process of diversification. The isolated nature of the areas in which he worked is illustrated by the WAM-FMNH trip to the Kimberley Islands that resulted in 46 islands being named. Many of these have endemic camaenid species. After his death, an additional island was named Solem Island. Hundreds of islands have not yet been surveyed; there are still many species to be collected on islands, in rainforest patches and elsewhere.

\section{ACKNOWLEDGEMENTS}

All three authors owe immense personal debts to Alan Solem, above and beyond the stimulation provided by his published work. We are grateful to Conservation and Land Management, Western Australia (CALM) for their encouragement and financial support of the symposium of which this paper is a part.

\section{REFERENCES}

All works by Alan Solem cited in the conventional manner are listed here, together with all the major monographs mentioned in the Systematics section. Other casual references are not listed, and this is not a comprehensive bibliography of his work in Australasia.

Barker, G.M. (2005). The character of the New Zealand land snail fauna and communities: some evolutionary and ecological perspectives. Records of the Western Australian Museum Supplement 68: 53-102.

Barker, G.M. and Mayhill, P.C. (1999). Patterns of diversity and habitat relationships in terrestrial mollusc communities of the Pukeamaru Ecological District, northeastern New Zealand. Journal of Biogeography 26: 215-238

Blackburn, T.M. and Gaston, K.J. (eds). (2003). Macroecology: Concepts and Consequences. Blackwell, Oxford.

Cameron, R.A.D. (1992). Land snail faunas of the Napier and Oscar Ranges, Western Australia: diversity, distribution and speciation. Biological Journal of the Linnean Society 45: 271-286.

Cameron, R.A.D. (1998). Dilemmas of rarity: biogeographical insights and conservation priorities for land Mollusca. Journal of Conchology, Special Publication 2: 51-60.
Cameron, R.A.D. and Cook, L.M. (2001). Madeiran snails: faunal differentiation on a small island. Journal of Molluscan Studies 67: 257-267.

Cameron, R.A.D., Cook, L.M. and Hallows, J.D. (1996). Land snails on Porto Santo: adaptive and nonadaptive radiation. Philosophical Transactions of the Royal Society of London, B. 351: 309-327.

Cowie, R.H. (1995). Variation in species diversity and shell shape in Hawaiian land snails: in situ speciation and ecological relationships. Evolution 49: 1191-1202.

Cowie, R.H. (1996). Pacific island land snails: relationships, origins and determinants of diversity. In Keast, A. and Miller, S.M. (eds), The Origin and Evolution of Pacific Island Biotas, New Guinea to Eastern Polynesia: Patterns and Processes.347-372. SPB Academic Publishing, Amsterdam.

Emberton. K.C. (1995). Land snail community morphologies of the highest diversity sites of Madagascar, North America and New Zealand, with recommended alternatives to height-diameter plots. Malacologia 36: 43-66.

Gittenberger, E. (1973). Beiträge zur Kenntnis der Pupillacea: III. Chondrininae. Zoologische Verhandelingen 127; 1-265.

Gittenberger, E. (1991). What about non-adaptive radiation? Biological Journal of the Linnean Society 43: 263-272.

Groombridge, B. (ed), (1992). Global Biodiversity: status of the Earth's living resources. Chapman and Hall, London.

Lomolino, M.V. (2000). A species-based theory of insular zoogeography. Global Ecology and Biogeography 9: 3958.

Martins, A.M. de Frias. (2005) The shaping of a species: the Azorean Drouetia (Pulmonata: Zonitidae: Oxychilus) as a model. Records of the Western Australian Museum Supplement 68: 143-157.

Moritz, C., Richardson, K.S., Ferrier, S., Monteith, G.B., Stanisic, J. Williams, S.E. and Whiffin, T. (2001). Biogeographical concordance and efficiency of taxon indicators for establishing conservation priority in a tropical rainforest biota. Proceedings of the Royal Society of London, B. 268: 1875-1881.

Mylonas, M., Giokas, S., Parmakelis, A., Triantis, K. and Vardinoyannis, K. (2004). Evolution and diversity of land snails in a laboratory of nature: the Aegean archipelagos. In Wells, F.E. (ed), Molluscan Megadiversity: Sea, Land and Freshwater. 103. Western Australian Museum, Perth.

Naggs, F. and Raheem, D. (2005). Sri Lankan snail diversity: faunal origins and future prospects. Records of the Western Australian Museum Supplement 68: 11-29.

Nekola, J.C. (2005). Richness and evenness of Eastern North American land snail communities. Records of the Western Australian Museum Supplement 68: 39-51.

Nekola, J.C. and Smith, T. (1999). Terrestrial gastropod richness patterns in Wisconsin carbonate cliff communities. Malacologia 41: 253-269.

Pokryszko, B.M. and Cameron, R.A.D. (2005). Geographical variation in the composition and richness of forest snail faunas in northern Europe. Records of the Western Australian Museum Supplement 68: 115-132. 
Schilthuizen, M. and Rutjes, H.A. (2001). Land-snail diversity in a square kilometre of tropical rainforest in Sabah, Malaysian Borneo. Journal of Molluscan Studies 67: 417-423.

Schmid, G. (1966). Die Mollusken des Spitzbergs. Natur und Landschaftsschutzgebiete, Baden Wïrtemburg 3: 596 701.

Seddon, M.B., Tattersfield, P., Herbert, D.G., Rowson, B., Lange, C.N., Ngereza, C., Warui, C.M. and Allen, J.A. (2005). Diversity of African forest mollusc faunas: what we have learned since Solem (1984). Records of the Western Australian Museum Supplement 68: 103-113.

Solem, A, (1976). Endodontoid Land Snails from Pacific Islands (Mollusca: Pulmonata: Sigmurethtra). Part I. Family Endodontidae. Field Museum of Natural History, Chicago.

Solem, A. (1978). Classification of the land Mollusca. In V. Fretter and J. Peake (eds), The Pulmonates. Vol 2. Systematics, Evolution, and Ecology. 49m97. Academic Press, London

Solem, A. (1979). Camaenid land snails from Western and central Australia (Mollusca: Pulmonata: Camaenidae), I. Taxa with trans Australian distributions. Records of the Western Australian Museum Supplement 10: 1-142.

Solem, A. (1981a). Camaenid land snails from Western and central Australia (Mollusca: Pulmonata: Camaenidae), II. Taxa from the Kimberley. Records of the Western Australian Museum Supplement 11: 143-320.

Solem, A. (1981b). Camaenid land snails from Western and central Australia (Mollusca: Pulmonata: Camaenidae), III. Taxa from the Ningbing Ranges and nearby areas. Records of the Western Australian Museum Supplement 11: 321-425.

Solem, A. (1981c). Land snail biogeography: a true snail's pace of change. In G. Nelson and D.E. Rosen (eds), Vicariance Biogeography: A Critique. 197-237. Columbia University Press, New York.

Solem, A, (1983). Endodontoid Land Snails from Pacific Islands (Mollusca: Pulmonata: Sigmurethra). Part II. Families Punctidae and Charopidae, Zoogeography. Field Museum of Natural History, Chicago.

Solem, A. (1984a). A world model of land snail diversity and abundance. In A. Solem and A.C. van Bruggen (eds), World-wide Snails, 6-22. E.J. Brill/W. Backhuys, Leiden.

Solem, A. (1984b). Camaenid land snails from Western and central Australia (Mollusca: Pulmonata: Camaenidae), IV. Taxa from the Kimberley, Westraltrachia Iredale, 1933 and related genera. Records of the Western Australian Museutm Supplement 17: 426705.

Solem, A. (1985a). Camaenid land snails from Western and central Australia (Mollusca: Pulmonata: Camaenidae), V. Remaining Kimberley genera and addenda to the Kimberley, Westraltrachia Iredale, 1933 and related genera. Records of the Western Australian Museum Supplement 17: 426-705.

Solem, A. (1985b). Simultaneous character convergence and divergence in Western Australian land snails. Biological Journal of the Linnean Society 24: 143-163.

Solem, A. (1986). Pupilloid land snails from South and Mid-west coasts of Australia. Journal of the Malacological Society of Australia 7: 95-124.
Solem, A. (1988). Maximum in the minimum: biogeography of land snails from the Ningbing Ranges and Jeremiah Hills, northeast Kimberley, Western Australia. Journal of the Malacological Society of Australia 9: 59-113.

Solem, A. (1989). Non-camaenid land snails of the Kimberley and Northern Territory, Australia. I. Systematics, affinities and ranges. Invertebrate Taxonomy 2: 455-604.

Solem, A. (1990a). Limitations of equilibrium theory in relation to land snails. Atti dei Convegni Lincei 85: 97116.

Solem, A. (1990b). How many Hawaiian land snail species are left? And what we can do for them. Bishop Museum Occasional Papers 30: 27-40.

Solem, A. (1991a) Land snails of Kimberley rainforest patches and biogeography of all Kimberley land snails. In N.L. McKenzie, R.B. Johnston and P.G. Kendrick (eds), Kimberley Rainforests, 145-246. Surrey Beatty and Sons, Pty Limited, Chipping Norton. NSW.

Solem, A. (1991b). Distribution and diversity patterns of Australian Pupilloid land snails (Molluscs: Pulmonata: Pupillidae, s.l.). The Veliger 34: 233-252.

Solem, A. (1992). Camaenid land snails from southern and eastern South Australia, excluding Kangaroo Island. Records of the South Australian Museum Monograph Series 2: 1-425.

Solem, A. (1993). Camaenid land snails from Western and central Australia (Mollusca: Pulmonata: Camaenidae), VI. Taxa from the red centre. Records of the Western Australian Museum Supplement 43: 983-1459.

Solem, A. (1997). Camaenid land snails from Western and central Australia (Mollusca: Pulmonata: Camaenidae), VII. Dampierland through the Nullabor. Records of the Western Australian Museum Supplement 50: 1461-1906.

Solem, A. and Christensen, C.C. (1984). Camaenid land snail reproductive cycle and growth patterns in semiarid areas of northwestern Australia. Australian Journal of Zoology 32: 491-492.

Solem, A., Climo, F.M. and Roscoe, D.J. (1981). Sympatric species diversity of New Zealand land snails. New Zealand Journal of Zoology 8: 453-485.

Solem, A. and Climo, F.M. (1985). Structure and habitat correlations of sympatric New Zealand land snail species. Malacologia 26: 1-30.

Solem, A. and McKenzie, N.L. (1991). The composition of land snail assemblages in Kimberley rainforests. In N.L. McKenzie, R.B. Johnston and P.G. Kendrick (eds), Kimberley Rainforests, 247-265. Surrey Beatty and Sons, Pty Limited, Chipping Norton.

Stanisic, J. (1994). The distribution and patterns of species diversity of land snails in eastern Australia. Memoirs of the Queensland Museum 36: 207-214.

Stanisic, J. (1997). An area of exceptional land snail diversity: the Macleay Valley, north-eastern New South Wales. Memoirs of the Museum of Victoria 56: $441-448$.

Stanisic, J. and Ponder, W.F. (2004). Forest snails in eastern Australia - one aspect of the other 99\%. In D. Lunney (ed.), The Conservation of Australia's Forest 
Fauna ( $2^{\text {nd }}$ edition). 127-149. Royal Zoological Society of New South Wales, Mosman NSW.

Tattersfield, P. (1998). Patterns of diversity and endemism in East African land snails, and the implications for conservation. Journal of Conchology, Special Publication 2: 77-86.

Triantis, K.A., Mylonas, M., Lika, K. and Vardinoyannis, K. (2003). A model for the species-area-habitat relationship. Journal of Biogeography 30: 19-27.

Triantis, K.A., Vardinoyannis, K. and Mylonas, M. (2005). Area and habitat relationships in island land snail faunas: an Aegean case study exploring the choros model. Records of the Western Australian Museum Supplement 68: 133-141.

de Winter, A.J. and Gittenberger, E. (1998). The land snail fauna of a square kilometre patch of rainforest in southwestern Cameroon: high species richness, low abundance and seasonal fluctuations. Malacologia 40: 231-250.

Woodruff, D.S. and Solem, A. 1990. Allozyme variation in the Australian camaenid land snail Cristilabrum primum: A prolegomenon for a molecular phylogeny of an extraordinary radiation in an isolated habitat. Veliger 22: 129-139. 